\title{
Evaluation of Etiology of Epistaxis and its Management in Dhulikhel Hospital
}

\author{
Shrestha I, Pokharel M, Shrestha BL, Dhakal A, Amatya RCM
}

\author{
Corresponding Author \\ Inku Shrestha \\ Department of ENT, Head \& Neck Surgery \\ Dhulikhel Hospital, Kathmandu University School of \\ Medical Sciences (KUSMS) \\ Dhulikhel, Kavre, Nepal \\ E-mail: shresthainku@gmail.com
}

Citation

Shrestha I, Pokharel M, Shrestha BL, Dhakal A, Amatya RCM. Evaluation of Aetiology of Epistaxis and its Management in Dhulikhel Hospital. Kathmandu Univ Med J 2015;49(1):49-55.

\section{ABSTRACT}

\section{Background}

Epistaxis is one of the most common and most difficult emergencies presenting in $7-14 \%$ of the general population each year. Although its lifetime incidence is about $60 \%$, only $6 \%$ require formal medical intervention but they can be serious and even life threatening.

\section{Objective}

The main objectives are to study different etiology, types, modality of treatment of epistaxis. Specific objective is also to find out if the modality of treatment is associated with age, site, amount of bleeding and etiology.

\section{Method}

It is a prospective, cross sectional, longitudinal, analytical study done in Department of ENT, Dhulikhel hospital, Kathmandu University School of Medical Sciences (KUSMS) from Aug. 2010 to Aug. 2013. Data was collected. This study was cleared through institutional review committee of hospital. Statistical analysis was done using SPSS 16.0.

\section{Result}

487 patients were studied during the period. There was significant association between age group with type of treatment ( $p$ value 0.002 ); and with admission ( $p$ value $<0.001$ ). Significance in the study was also shown in the correlation between site of bleeding and the type of treatment and also with alcohol intake with site of bleeding ( $p$ value $<0.001$ ). However there was no significance between hypertension and the type of treatment methods chosen ( $p$ value $>0.01$ ).

\section{Conclusion}

Management of epistaxis is challenging. Most are managed by non surgical means whereas some by surgical treatment. Non surgical treatment is still useful, safe and cost effective. Type of treatment and need for hospital stay is related to age and site of bleeding.

\section{KEY WORDS}

Age group, epistaxis, modality of treatment, site of bleeding 


\section{INTRODUCTION}

Epistaxis is one of the most common and most difficult emergencies presenting in $7-14 \%$ of the general population each year. ${ }^{1-3}$ Although its lifetime incidence is about $60 \%$, only $6 \%$ require formal medical intervention but they can be serious and even life threatening. ${ }^{4}$ Most patients who develop epistaxis do not seek medical attention because bleeding is minor and usually stops quickly. However at other times it could be full blown life threatening major hemorrhage.

The causes of epistaxis are varied and both local and systemic factors may contribute. Several factors have been shown to correlate strongly with epistaxis like: season of year (winter being more common). Sex (more common in males): age (epistaxis in younger tends to be anterior and more minor where as the more severe posterior epistaxis tends to be seen in those greater than 50 years of age $).{ }^{1}$

The modalities of treatment depend of the nature. Historical literature suggests simplest treatment for a nose bleed as pinching the ala nasi, also called as Hippocratic technique. ${ }^{3}$ Treatment can be classified from least invasive to most invasive. As a part of physical examination, the source of the bleeding should be identified, this is clearly the most important aspect of determining proper treatment.

Across different centers, investigation profiles and treatment preferences vary. There are areas of controversies and non standardized practice exists. This situation needs to be addressed in an evidence based fashion.

The main objectives are to study the different etiology, types of epistaxis and its modality of treatment. Specific objective is also to find out if the modality of its treatment is associated with age, site, amount of bleeding and etiology.

\section{METHODS}

This is a prospective, cross sectional, longitudinal, analytical study done in department of ENT-HNS; Dhulikhel teaching hospital, Kathmandu University School of Medical Sciences (KUSMS) from Aug. 2010 to Aug. 2013. A total number of 487 patients were included in the study. These patients were received through emergency and outpatients department of ENT and also as referral through other departments during the study period.

\section{Following data were collected:}

- Demographics (age, gender)

- Other concurrent illness or medications

- History of epistaxis (hypertension, any previous episodes over last 6 months, previous visits to doctors, nasal procedures/surgeries)

- History of medication with hemorrhagic risk currently or stopped within last 10 days (Platelet inhibiters, NSAIDS, Salicilate derivatives, Vitamin K antagonists, beta lactams, antidepressants, long term corticosteroids)

- History of pathology with hemorrhagic risk - chronic alcoholism, hepatic insufficiency.

- Initial clinical examination

Vitals (mainly BP)

Presence of nasal Packing

Bleeding Characteristics- Not copious (<250 ml)

Copious bleeding (>250 ml)

Discontinuous bleeding $<6 \mathrm{hrs}$

Discontinuous bleeding $>6 \mathrm{hrs}$

- Initial treatment initial maneuvers- head forward, blowing of nose, suction of clot, use of vasoconstrictor

- Local procedures - bidigital pressure, chemical cautery and anterior nasal packing.

- Initial treatment and following results.

\section{Selection Criteria}

Inclusion criteria- all patients with epistaxis coming to the hospital during the period of study

Exclusion criteria-patients who were lost for follow up.

\section{ETHICS}

This study was cleared through institutional review committee of hospital. Patients were informed verbally by the treating specialist on call and were shown written information about the study.

After resuscitation of the patients they underwent a detailed history taking and a thorough general examination, systemic examination and examination of nose, throat and ears with special emphasis to identify the site of bleeding. Relevant blood and radiological investigations were sent. Data was collected using a structured performa prepared for the purpose. Data collected included; patient's demographics, site and side of bleeding, time and season, cause, management modalities, need for admission, length of hospital stay, outcome. The data collected were entered in SPSS version 16.0 for analysis.

\section{Statistical analysis:}

Statistical analysis was done using SPSS 16.0. Initially, the variables were presented as descriptive data .Then an exploratory analysis was done to identify the risk factors influencing epistaxis failures. In this process, the variables for previous patient history, history of epistaxis, bleeding characteristics and course and final disposition of patients were put together and their independence tested by the chi square test.

\section{RESULTS}

During the study period, a total of 487 patients were 
treated and studied .Patients with epistaxis formed $1.62 \%$ of the total ENT out patient's attendance and $28 \%$ of the total cases admitted in the ENT wards. Mean age \pm SD was $33.4 \pm 2.17$. Maximum incidence was found in age group $11-20$ years $(20.3 \%)$ with a range of 1 to 85 . (Table 1 )

Table 1. Age in years

\begin{tabular}{|lll|}
\hline Age in years & Frequency $(\mathbf{n = 4 8 7})$ & Percentage (\%) \\
\hline $0-10$ & 71 & 14.6 \\
\hline $11-20$ & 99 & 20.3 \\
\hline $21-30$ & 89 & 18.3 \\
\hline $31-40$ & 59 & 12.1 \\
\hline $41-50$ & 57 & 11.7 \\
\hline $51-60$ & 47 & 9.7 \\
\hline $61-70$ & 24 & 4.9 \\
\hline $71-80$ & 37 & 7.6 \\
\hline $81-90$ & 4 & 0.8 \\
\hline
\end{tabular}

Patients less than 50 years were 368 (75.6\%) and more than 50 years were 119 (24.4\%). Males (307) predominated in both indoor and outdoor patients with a male to female ratio of 1.7:1. The nasal cavity most involved was left 228 (47\%) compared to right 188 (38.6\%). Bilateral involvement was seen in $70(14.4 \%)$ cases. Higher incidence was also noticed during winters 205 (42.1\%), followed by summer $140(28.7 \%)$, then autumn $84(17.2 \%)$ and least in spring 58 (11.9\%). Circadian rhythm was also noted where we found epistaxis to be more during night 183 (37.6\%), followed by evening 172 (35.3\%) and finally morning 132 (27.1\%). Previous history of hypertension (HTN) is seen in $26.3 \%$ of cases (128). History of taking medications with hemorrhagic risk using currently or stopped within the last 10 days was $3.5 \%$ ( 17 ) and history of epistaxis in last six months was seen in $9(1.8 \%)$ patients. About alcohol intake, there were 45 patients (9.2\%) who take alcohol regularly, 120 patients (24.6\%) who drink occasionally and 322 (66.1\%) who do not give history of alcohol intake. (Table 2)

The commonest cause of epistaxis was trauma 162 (33.3\%) cases, followed by cardiovascular related 133 (27.3\%), idiopathic causes and inflammatory condition related causes followed the leading with 63 (12.9\%) each.(Table 3)

According to bleeding site, 417 (85.6\%) had anterior bleeding and $36(7.4 \%)$ had posterior bleeding where as in $34(7 \%)$ cases exact site could not be identified and has been termed diffuse.

Regarding treatment; Majority (406) of patients were treated by non surgical methods (81.9\%); among which local cauterization in 304 (62.4\%), anterior nasal packing in $84(17.2 \%)$ and posterior nasal packing in 11 (2.3\%) of total patients. Surgical methods were chosen in more intractable and severe cases which included local electrocautery in $17(3.5 \%)$, endoscopic sphenopalatine cauterization in $11(2.3 \%)$. Other surgeries like nasal fracture reduction in cases of fracture of nasal bone, medial maxillectomy for
Table 2. Demographic and clinical characteristics

\begin{tabular}{|c|c|c|}
\hline Patient included & Frequency $(n=487)$ & Percentage (\%) \\
\hline \multicolumn{3}{|l|}{ Gender } \\
\hline Male & 307 & 63 \\
\hline Female & 180 & 37 \\
\hline \multicolumn{3}{|l|}{ Age } \\
\hline$<50$ years & 368 & 75.6 \\
\hline$>50$ years & 119 & 24.4 \\
\hline \multicolumn{3}{|l|}{ Site of involvement } \\
\hline Left & 229 & 47 \\
\hline Right & 188 & 38.6 \\
\hline Bilateral & 70 & 14.4 \\
\hline \multicolumn{3}{|l|}{ Circadian rhythm } \\
\hline Morning & 132 & 27.1 \\
\hline Evening & 172 & 35.3 \\
\hline Night & 183 & 37.6 \\
\hline \multicolumn{3}{|l|}{ Season } \\
\hline Spring & 58 & 11.9 \\
\hline Summer & 140 & 28.7 \\
\hline Autumn & 84 & 17.2 \\
\hline Winter & 205 & 42.1 \\
\hline \multicolumn{3}{|l|}{ Previous history } \\
\hline HTN & 128 & 26.3 \\
\hline $\begin{array}{l}\text { Medications with a hemor- } \\
\text { rhagic risk currently or } \\
\text { stopped within the last } 10 \\
\text { days }\end{array}$ & 17 & 3.5 \\
\hline Epistaxis in Prev 6 months & 10 & 2.05 \\
\hline \multicolumn{3}{|l|}{ alcohol intake } \\
\hline $\begin{array}{l}\text { non drinkers (never drinks) } \\
\text { occasional drinkers (< once }\end{array}$ & 322 & 66.1 \\
\hline $\begin{array}{l}\text { a week) } \\
\text { regular drinkers (> once a }\end{array}$ & 120 & 24.6 \\
\hline week) & 45 & 9.2 \\
\hline
\end{tabular}

Table 3. Causes of epistaxis

\begin{tabular}{|c|c|c|}
\hline Causes & $\begin{array}{l}\text { Frequency } \\
n=487\end{array}$ & $\begin{array}{l}\text { Percentage } \\
\%\end{array}$ \\
\hline Trauma ( injury + surgery ) & 162 & 33.3 \\
\hline $\begin{array}{l}\text { Cardiovascular related (Hypertension + } \\
\text { atherosclerosis) }\end{array}$ & 133 & 27.3 \\
\hline Idiopathic & 63 & 12.9 \\
\hline $\begin{array}{l}\text { Inflammatory diseases (chronic rhinosi- } \\
\text { nusitis) }\end{array}$ & 63 & 12.9 \\
\hline Foreign bodies ( living / non living ) & 40 & 8.2 \\
\hline Tumors( benign/malignant) & 21 & 4.3 \\
\hline Blood dyscrasia (including liver diseases ) & 5 & 1.0 \\
\hline
\end{tabular}

inverted pappiloma, septoplasty, spur excision for deviated nasal septum, Functional endoscopic sinus surgery, excision for nasal hemangioma or masses, endoscopic excision of Juvenile nasopharyngeal angiofibroma (JNA ) etc, were done in $59(12.1 \%)$ of total cases.(Table 4$)$

182 (37.3\%) patients were admitted whereas 305 (62.6\%) were treated as outpatient basis. Among the outpatients there was $100 \%$ success rate and sent home the same day. Among the admitted patients, 177 (97.2\%) were discharged after successful treatment where as $5(2.8 \%)$ cases were not. One patient with biopsy report as squamous cell carcinoma from the nasal mass was referred to cancer 
Table 4. Treatment modalities

\begin{tabular}{|c|c|c|}
\hline Treatment modality & $\begin{array}{l}\text { Frequency } \\
n=487\end{array}$ & $\begin{array}{l}\text { Percentage } \\
\%\end{array}$ \\
\hline \multicolumn{3}{|l|}{ Non surgical } \\
\hline Local cauterization & 304 & 62.4 \\
\hline Anterior packing & 84 & 17.2 \\
\hline Posterior packing & 11 & 2.3 \\
\hline \multicolumn{3}{|l|}{ Surgical } \\
\hline Local Electrocautery & 17 & 3.5 \\
\hline SPA ligation & 11 & 2.3 \\
\hline Other surgeries & 59 & 12.1 \\
\hline
\end{tabular}

Table 5. Outcome

\begin{tabular}{|lll|}
\hline & Frequency $(\mathbf{n = 4 8 7})$ & Percentage \\
\hline Outpatients & & \\
\hline Successfully treated & 305 & 63.7 \\
\hline In Patients & & \\
\hline Discharged & 177 & 36.3 \\
\hline Referred & 4 & 0.8 \\
\hline LAMA & 1 & 0.2 \\
\hline
\end{tabular}

hospital for chemo-radiotherapy. Four were referred to other departments. Three were referred to internal medicine department for pleural effusion, cardiac failure with corpulmonale and one with alcoholic liver diseases. 1 patient Left against medical advice (LAMA) during the admission. (Table 5)

Significant association was seen between the two broad age groups and the fact that admission was required or not
Table 6. Statistical significance

\begin{tabular}{|c|c|c|c|c|c|}
\hline & \multicolumn{3}{|c|}{ Admitted or not } & \multicolumn{2}{|c|}{ Treatment } \\
\hline \multicolumn{4}{|l|}{ Age group } & $\begin{array}{l}\text { Non } \\
\text { surgical }\end{array}$ & Surgical \\
\hline \multicolumn{4}{|l|}{ Less than 50} & 318 & 50 \\
\hline \multirow{3}{*}{$\begin{array}{l}\text { More than or } \\
\text { equals to } 50\end{array}$} & & & & 88 & 31 \\
\hline & \multicolumn{3}{|c|}{$P$ value -0.000} & \multicolumn{2}{|c|}{$P$ value -0.002} \\
\hline & \multicolumn{3}{|c|}{ Alcohol intake } & \multicolumn{2}{|c|}{ Treatment } \\
\hline Site of Bleeding & None & $\begin{array}{l}\text { Occa- } \\
\text { sional }\end{array}$ & $\begin{array}{l}\text { Regu- } \\
\text { lar }\end{array}$ & $\begin{array}{l}\text { Non } \\
\text { surgical }\end{array}$ & Surgical \\
\hline Anterior & 299 & 94 & 24 & 366 & 51 \\
\hline Posterior & 10 & 12 & 14 & 20 & 16 \\
\hline \multirow[t]{3}{*}{ Diffuse } & 13 & 14 & 7 & 20 & 14 \\
\hline & \multirow{2}{*}{\multicolumn{3}{|c|}{$P$ value- 0.000}} & \multicolumn{2}{|c|}{$P$ value- 0.000} \\
\hline & & & & \multicolumn{2}{|c|}{ Treatment } \\
\hline \multicolumn{4}{|l|}{ Hypertension } & $\begin{array}{l}\text { Non } \\
\text { surgical }\end{array}$ & Surgical \\
\hline \multicolumn{4}{|l|}{ Yes } & \multicolumn{2}{|l|}{103} \\
\hline \multirow[t]{2}{*}{ No } & & & & \multicolumn{2}{|l|}{303} \\
\hline & & & & \multicolumn{2}{|c|}{$P$ value- 0.305} \\
\hline
\end{tabular}

with a $p$ value $<0.001$. Significance in the study was also shown in the correlation between site of bleeding and the type of treatment with Pearson's P value $<0.001$. Significant relation is also seen with alcohol intake and site of bleeding ( $p$ value $<0.001$ ). We also found a relationship between age group ( $<50$ years, $>50$ years ) and the type of treatment. There was significant association on chi square test with a $p$ value of 0.002 . However there was no significance between HTN and the type of treatment methods chosen. ( $P$ value $>0.01$ ). (Table 6)

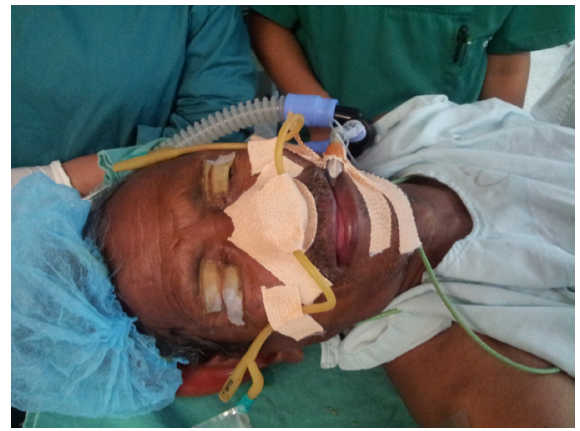

Figure 1. Picture showing Posterior Nasal Packing with Foley's catheter.
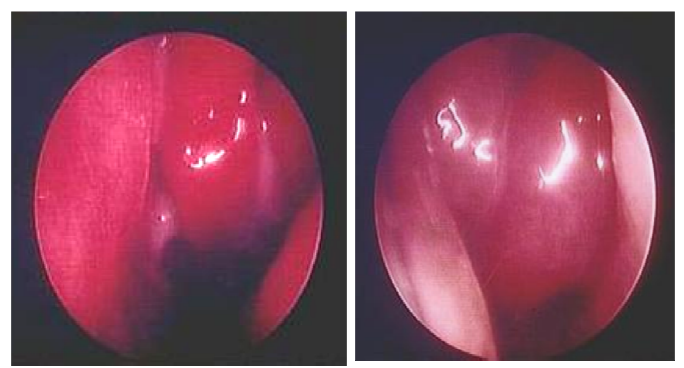

Figure 4. Endoscopic picture of JNA

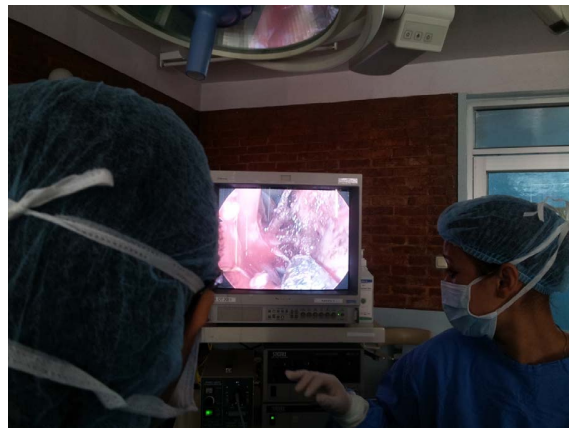

Figure 2. Brachches of SPA being cauterized

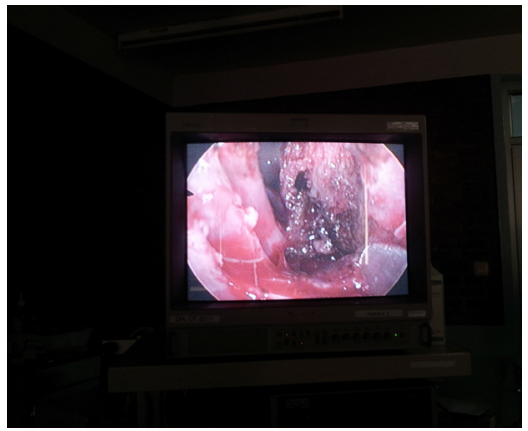

Figure 3. Post cautery Sphenopalatine Fossa.

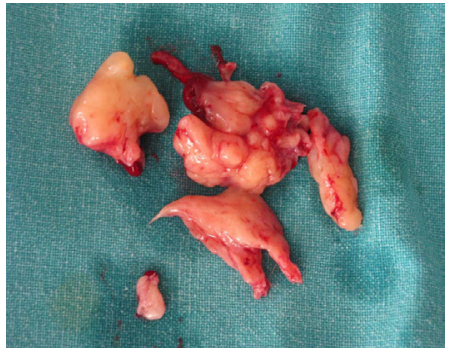

Figure 5. Picture of Inverted pappiloma post excision. 


\section{DISCUSSION}

487 patients taken in study were the patients that came to department of ENT of Dhulikhel Hospital (KUSMS) with epistaxis during the study period. More patients were seen in age group 11-20 years and. More patients were $<50$ years, $>50$ years. Epistaxis was found to be more prevalent in the young adults, which is in agreement with study at a tertiary care hospital in Northwestern Tanzania by Gilyoma and Chalya 5 which is also true in Nigeria by Kodia AM et al 6 but in contrary to study in Dehradun, India by Saurabh Varshney and R. K. Saxena. ${ }^{7}$ The low age incidence in our study may be due to fact that the majority of our patients who had traumatic epistaxis 33\% tended to be younger than those with atraumatic epistaxis. Young people are the most active in population and so vulnerable to trauma from nose picking especially among children and also fights, road traffic accidents causing epistaxis. They are also the more adventurous group are most often on road for economic well being. ${ }^{5}$

The assumption that older individuals, who have lost the elastic and contractile properties of their arteries, are prone to more severe nosebleeds than younger individuals and requires hospitalization and aggressive management ${ }^{8,9}$; is confirmed in our sample of patients.

Age <50 were 368 (75.6\%), and >50 were 119 (24.4\%) were divided so to mark a difference between elderly and younger generation. For this project, we have used 50 years of age and older as the general definition of an older person depending on the setting, the region and the country. ${ }^{10}$ Male predominance like in our study with has been reported in literature..$^{5-7,11}$ Unilateral involvement with left sided predominance is seen like in study by Varshney $\mathrm{S}$ and Saxena RK, ${ }^{7}$ and Urvasi $\mathrm{R}$ et al. ${ }^{12}$

$86 \%$ have anterior bleeding like in study by Gilyoma, ${ }^{5}$ Iseh. $\mathrm{KR},{ }^{13}$ Klossek, ${ }^{14}$ Hussain $\mathrm{G},{ }^{15}$ and Middleton $\mathrm{P}$ et al. ${ }^{16}$ all leading to same pattern throughout the world favoring anterior bleeding.

Increase incidence of epistaxis in winter was seen in our study which is in agreement with Wormald PJ, Varshney $\mathrm{S}$, Petruson B, Purkey MR. ${ }^{2,7,11,17}$ and it may be attributed to high wind velocity and dryness which favor crust formation in the nasal cavity. Epistaxis seen more in the night followed by evening and finally by morning in our study is not corresponding completely with study by Roberto Manfredini et al. ${ }^{18}$ where they found a primary peak in the morning, a smaller secondary peak in the evening, and a nocturnal nadir. Regarding Alcohol intake, there were 9.2\% who drank regularly and $24.6 \%$ who drank occasionally. There was significance between history alcohol intake and site of bleeding suggesting that drinking alcohol was a risk factor for the severity of bleeding. They are suggested to be due to the effects of alcohol in reducing platelet aggregation and prolonging bleeding time. Like suggested by Middleton $\mathrm{PM},{ }^{16}$ we have defined our patients as non- drinkers if they never drank alcohol; occasional drinkers if they drank alcohol less than once a week; and regular drinkers if they drank alcohol more than once a week like in study by McGarry GW. ${ }^{19}$

A committed search for the bleeder as well as a deliberate effort to find the cause of epistaxis is necessary, ${ }^{3,6,7}$ because too many cases of epistaxis are grouped as idiopathic or primary. ${ }^{6,7}$ Trauma was the dominant cause of epistaxis in our study like in study by Gilyoma et al. ${ }^{5}$ which was in discordance with the findings by Kodiya AM et al. ${ }^{6}$ and Varshney et al. ${ }^{7}$ where idiopathic causes predominated. No cause was identified in $12.9 \%$ patients in this study so were labeled as idiopathic, That is a known entity reported in literature. ${ }^{6,7,20}$ Trauma in our study population varied from minor self inflicted Injuries such as digital trauma to severe degrees of maxillofacial trauma due to accidents. The nose being the most prominent part of the face is most susceptible to craniofacial injury. Most of the patients were victims of RTA and had nasal bone fractures along with other maxillo facial injuries. This is also in accordance with study by Urvasi Razdan et al. ${ }^{12}$ where trauma was the commonest case for outdoor patients. HTN (hypertension) is one of the major causes of epistaxis (27.3\%) and we also identified association between blood pressure levels and presence of enlarged blood vessels in the nasal mucosa (seen during rhinoscopy or endoscopy). It may be possible that enlarged aspect of the vessel may represent some degree of degeneration of the blood vessel walls, making them prone for bleeding as suggested by Neto JFL. ${ }^{8}$ This is also in accordance with study by Glioma, ${ }^{5}$ where HTN is due to poor blood pressure control. Varshney and Saxena, ${ }^{7}$ in India recorded HTN as second commonest cause of epistaxis followed by idiopathic causes and also study by Charles R in Bristol General Hospital. ${ }^{21}$ So this study also emphasizes on the regular blood pressure check and compliance to antihypertensive medications.

Rhino sinusitis may be a coexisting factor, particularly in children, and may lead to increased inflammation, nose blowing, or potentially, digital trauma, resulting in epistaxis. ${ }^{19}$ Inflammatory causes like rhino sinusitis or different causes of rhinitis as cause of epistaxis were seen in $12.9 \%$ of causes. After the acute bleeding episode was stopped, required medications were also prescribed for the rhino sinusitis or other inflammatory processes. ${ }^{22}$ Foreign bodies accounted to (40 cases) $8.2 \%$ of total patients were also causes of unilateral epistaxis especially in children. The foreign bodies that were found were of different kinds of both living and non living. Tumors like Inverted pappiloma were seen in cases and JNA in one patient. The most common presenting symptoms of patients with JNA are unilateral nasal obstruction occurring in $91 \%$ and epistaxis occurring in $63 \%$ of patients. ${ }^{23}$ Blood dyscrasia was seen in five cases (1\%) which is much lesser than in study by Razdan $U,{ }^{12}$ or Hussain et al. ${ }^{15}$ Deranged LFTs seen in two cases of patients with alcohol dependence. 
Immediate management included an Advanced Life Support-Type ABC (Airway, Breathing, and Circulation) assessment and resuscitation. Epistaxis is not usually an immediate airway threat but patients should be sat upright and encouraged to lean forward and clear any clots form their pharynx. An assessment of blood loss is made (time, volume, amount). Local cauterization was done in 304 cases $(62.4 \%)$ with silver nitrate $75 \%$, but it is difficult in contest of active bleeding where electrocautery was more effective. Electro cautery was done in 17 cases (3.5\%) of active and uncontrolled bleeding. Control of bleeding was also achieved by tamponade using either anterior (17.2\%) or posterior packing (2.3\%). once a pack is inserted, it is usually recommended that it is left in place for at least 24 hrs necessitating admission. Postnasal packs are extremely uncomfortable and are prone to cause significant hypoxia, hospitalization, oxygen therapy via face mask and in some cases sedation are required : a combination that increases the risk of aspiration and hypoxia. ${ }^{23,24,17}$ patients (3.5\%) were taken to theater for electro coagulation as theater equipment and anesthesia will facilitate in visualization of the bleeding site, bleeding control and direct cautery. Where this method remains impossible or uncertain then arterial cautery or ligation. 11 cases (2.3\%) had successful sphenopalatine artery ligation as Ninety percent of the nasal mucosa received its blood supply via the SPA. ${ }^{25}$

SPA ligation is more successful, possibly because of difficulties completing the other procedures or a failure to address more distal collateral circulation. When compared with traditional packing techniques, SPA ligation has been shown to provide improved patient satisfaction reduced overall admissions and overall cost. ${ }^{24}$ However ligation or cauterization of all the SPA branches is essential. Other surgeries totaled to $12.1 \%$ (59 cases). Types of other surgeries were fracture reduction, surgeries for

\section{REFERENCES}

1. Weiss NS. Relation of high blood pressure to headache, epistaxis, and selected other symptoms. The United States Health Examination Survey of Adults.N Engl J Med. 1972; 287:631-3

2. Wormald PJ. Epistaxis. Byron and Bailey's Head and Neck Surgery Otolaryngology. $4^{\text {th }}$ ed. Philadelphia: Lippincott Williams and Wilkins;2006.p.505-14.

3. McGarry. Epistaxis. Scott-Brown's otorhinolarngology, Head and Neck surgery. $7^{\text {th }}$ ed. London:Edward Arnold Publishers; 2008.p.1596-1608

4. Tami AT, Merrel JA. Epistaxis. Ballenger's Otorhinolaryngology. Centennial ed. Connecticut: BC Decker; 2009.p.551-55

5. Gilyoma JM, Chalya PM. Etiological profile and treatment outcome of epistaxis at a tertiary care hospital in Northwestern Tanzania: a prospective review of 104 cases. BMC ear, Nose and throat Disorders. 2011; $11: 8$

6. Kodiya AM, Labaran LS, Musa E. Epistaxis in Kaduna, Nigeria: a review of 101 cases. African Health Sciences. 2012; 12(4):479-82

7. Varshney S, Saxena RK. Epistaxis : a retrospective clinical study. Indian J Otolaryngol Head Neck Surg. 2005; 57(2): 125-9.

8. Neto JFL, Fuchs FD, Facco SR, Gus M, Fasolo L, mafessoni R, Gleissner AL. Is Epistaxis Evidence of End Organ damage In patients with Hypertension. The Laryngoscope. 2009; (109): 1111-15 maxillofacial trauma, medial maxillectomy for inverted pappiloma, hemangioma excision and one case of transnasal endoscopic resection of Juvenile Nasopharyngeal Angiofibroma Stage 1 . Some patients required suturing of maxillofacial lesions or intra nasal mucosa. One patient required Tran nasal approach- endoscopic resection of JNA. It was done in stage 1 (Andrew's classification); that is tumor limited to nasopharynx and nasal cavity. This approach has advantages over traditional open approach as it avoids osteotomies in young population, which have been implicated in inhibiting facial growth. It also leads to $50 \%$ reduction in intraoperative blood loss. In addition, endoscopes offer magnification and angled views for excellent tumor visualization not provided by open procedures. JNA They also reduces hospital stay and local recurrence. ${ }^{23}$ The mean length of hospital stay in our admitted patients was 1.39 days with maximum 9 days and minimum 1 day; which is lower than Gilyoma, ${ }^{5}$ where it is 7.2 days.

The present study was limited in some aspects like unavailability of chemo radiotherapy in the same site of treatment. It is also a single institute based analysis; the treating surgeons are the investigators of the study, so some biasness cannot be ruled out.

\section{RESULTS}

Trauma either self inflicted or iatrogenic or due to accident remains the most common etiological factor for epistaxis in our setting. Most were managed in the outpatient department by non surgical means whereas some were admitted for surgical treatment. Non surgical treatment is still useful, safe and cost effective. Type of treatment and need for hospital stay is related to age and site of bleeding.

9. Page C, Biet A, Liabeuf S, Strunski V, Fournier A. Serious spontaneous epistaxis and hypertension in hospitalized patients. Eur Arch Otorhinolaryngol. 2011;268(12):1749-53

10. World Health Organization (WHO). Information Needs for Research, Policy and Action on Ageing and Older Adults. Zimbabwe,2000

11. Petruson B. Epsitaxis: a clinical study with special reference to fibrinolysis. Acta Otolaryngol. 1974;317( suppl):1-73

12. Urvashi R, Raizada RM, Chaturvedi VN. Epistaxis: study of etiology, site and side of bleeding. Indian journal of Medical Sciences. 1999; 53 (12):545-52.

13. Iseh KR, Muhammad Z. Pattern of epistaxis in Sokoto, Nigeria: A review of 72 cases, ann Afr Med. 2008; 7(3): 107-11.

14. Klossek JM, Dufour $X$ et al. Epistaxis and its management: an observational pilot study carried out in 23 hospital centres in France. Rhinology. 2006;44:151-5.

15. Hussain G, Iqbal M, Shah SA, Said Mohammad. Evaluation of Aetiology and efficacy of manamement protocol of epistaxis. J Ayub Med Coll Abbottabad. 2006;18(4):62-5

16. Middleton PM. Epistaxis. Emergency Medicine. 2004;16: 428-440. 
17. Purkey MR, Seebkin Z, Chandra R. Seasonal Variation and predictors of epistaxis. Laryngoscope. 2014; (9): 124

18. Manfredini R, Portaluppi F, Salmi R, Martini A, Gallerani M Circadian variation in onset of epistaxis: analysis of hospital admissions. BMJ. 2000;321(7269):1112

19. McGarry GW, Gatehouse S, Hinnie J. Relation between alcohol and nose bleeds. BMJ. 1994;309(6955):640

20. Pope LE, Hobbs CG. Epistaxis an update on current. Postgrad Med J. 2005; 81(955): 309-14

21. Charles R, Corrigan E. Epistaxis and hypertension. Postgradulate Medical Journal. 1977;(53):260-61.
22. Gifford T.O., Orlandi R.R. Epistaxis. Otplaryngologic clinics of North America. 2008; (41):525-536.

23. Blount A, Riley KO, Woodworth BA. Juvenile Nasopharyngeal Angiofibroma. Otolaryngol Clin N AM. 2011;(44):989-1004

24. Barnes M.L., White P.S. Epistaxis: A contemporary evidence based Approach. Otolaryngol Clin N Am. 2012;(45):1005-1017

25. Loughran S, Hilmi O, McGarry GW. Endoscopic sphenopalatine artery ligation-when, why and how to do it. An online video tutorial. Clin Otolaryngol. 2005; (30): 539-43. 